\title{
注浆成型结合真空发泡法制备梯度多孔氮化硅陶瓷
}

\author{
邓 健 ${ }^{1,2}$, 姚冬旭 ${ }^{1}$, 夏咏锋 ${ }^{1}$, 左开慧 ${ }^{1}$, 尹金伟 ${ }^{1}$, 曾宇平 ${ }^{1}$
}

(1. 中国科学院 上海硅酸盐研究所, 高性能陶瓷和超微结构国家重点实验室, 上海 200050; 2. 中国科学院大学, 北京 100049)

摘 要: 通过注浆成型结合真空发泡制备出具有明显梯度结构的多孔氮化硅陶瓷。该工艺在浆料中加入发泡剂, 然 后注入底部为石膏的模具中, 抽真空保压并恒温保存, 浆料在低压下会形成孔径梯度结构。研究发现, 气压对样品 的梯度结构有较明显影响, 随着气压由 $80 \mathrm{kPa}$ 降低到 $9 \mathrm{kPa}$, 样品气孔率由 $59.01 \%$ 提高到 $80.85 \%$, 当气压为 $80 \mathrm{kPa}$ 时, 样品无宏观梯度结构, 随着气压的降低, 梯度结构趋于明显。压录法测试表明, $9 \mathrm{kPa}$ 气压制备的样品孔径分布 比较分散，具有 $0.5 、 20 、 30 、 40 、 60 、 100$ 和 $200 \mu \mathrm{m}$ 等多种气孔孔径值。该工艺具有简易、廉价，孔径分布和气 孔率可调的优点，可实现大尺寸、复杂形貌材料的制备，为梯度多孔材料的制备方法提供了新思路。

关 键 词: 梯度; 发泡; 多孔; 氮化硅

中图分类号: TQ174 文献标识码: A

\section{Gradient Porous Silicon Nitride by Slip Casting and Vacuum Foaming}

\author{
DENG Jian ${ }^{1,2}$, YAO Dong-Xu ${ }^{1}$, XIA Yong-Feng ${ }^{1}$, ZUO Kai-Hui ${ }^{1}$, YIN Jin-Wei ${ }^{1}$, ZENG Yu-Ping ${ }^{1}$
}

(1. State Key Laboratory of High Performance Ceramics and Superfine Microstructures, Shanghai Institute of Ceramics, Chinese Academy of Sciences, Shanghai 200050, China; 2. University of Chinese Academy of Sciences, Beijing 100049, China)

\begin{abstract}
Gradient porous silicon nitride was fabricated by a combination method of slip casting and vacuum foaming. Firstly, foaming agent was added into $\mathrm{Si}_{3} \mathrm{~N}_{4}$ aqueous slurry, then the uniformly stirred slurry was poured into the mold with plaster as base. Under low pressure and steady temperature, a green body with gradient pores was formed. Based on our research, the gradient structure and porosity were greatly influenced by the vacuum pressure. With the pressure decrease from $80 \mathrm{kPa}$ to $9 \mathrm{kPa}$, the porosity increased from $59.01 \%$ to $80.85 \%$ and the gradient structure became more noticeable. When the pressure was $80 \mathrm{kPa}$, the sample obtained a uniform pore structure. After the pressure being decreased to $9 \mathrm{kPa}$, the sample obtained dispersed pore size distribution including values of $0.5,20,30,40,60$, 100 and $200 \mu \mathrm{m}$ measured through mercury intrusion method. Gradient porous ceramics with adjustable porosity and pore size distribution, as well as achievable complex shape and large scale, may fabricate through this simply and low cost method.
\end{abstract}

Key words: gradient; foaming; porous; silicon nitride

多孔氮化硅陶瓷以其独特的三维连通网状气孔 结构、高气孔率以及超强的化学惰性和高温性能而
被广泛应用于过滤器、热交换器、传感器、催化剂 载体和能源化工等方面 ${ }^{[1]}$ 。为了在一些特殊行业或

收稿日期: 2016-02-01; 收到修改稿日期：2016-03-28

基金项目: 中国科学院上海硅酸盐研究所高性能陶瓷和超微结构国家重点实验室主任青年基金(SKL201401); 青年科学基 金(51501215)

Science Foundation for Youth Scholar of State Key Laboratory of High Performance Ceramics and Superfine Microstructures, Shanghai Institute of Ceramics, Chinese Academy of sciences (SKL201401); Youth Science Foundation (51501215)

作者简介: 邓 健(1989-), 男, 硕士研究生. E-mail: djmengwu@student.ustc.edu.cn

通讯作者：曾宇平，研究员. E-mail: yuping-zeng@mail.sic.ac.cn 
领域, 如吸声隔音、雷达电磁波传导等领域延伸其 应用范围, 研究者们对梯度多孔氮化硅陶瓷展开了 广泛研究 ${ }^{[2-4]}$ 。

梯度多孔陶瓷是一类具有孔径或气孔率定向梯 度分布的多孔陶瓷, 可以采用多种工艺制备, 如干 压法 ${ }^{[5]} 、$ 牺牲模板法 $^{[6]}$ 、离心法 ${ }^{[7]}$ 、定向浸润法 ${ }^{[8]} 、$ 注射成型 ${ }^{[9]}$ 等。然而上述制备工艺存在工艺复杂、 样品形状简单和成本难控制等不足。注浆成型法 ${ }^{[10]}$ 是一种较好的制备多孔材料的方法, 但是其制备的 样品气孔率范围过窄。发泡法是一种制备高气孔率 陶瓷材料的常见制备工艺, 通过发泡法可以实现超 过 90\%的超高气孔率, 但如何实现梯度结构是一大 难题。最近, 有研究者采用真空发泡法制备具有明 显梯度多孔结构的氮化硅多孔陶瓷, 并获得了较好 的效果 ${ }^{[11]}$ 。但该方法采用的冷冻干燥工艺耗时长、 耗能多。

本工作结合注浆成型和真空发泡工艺, 制备了 具有明显孔径分布的多孔氮化硅梯度陶瓷, 该成型 工艺简便易操作, 生产成本低。研究还解释了梯度 形成的原因, 并研究了气压大小对样品梯度结构及 其性能的影响。

\section{1 实验方法}

\section{1 原料}

氮化硅粉 (江苏安赛美新能源科技有限公司) , $\alpha$ 相含量 $\geqslant 92 \%$, 平均粒径 $0.42 \mu \mathrm{m}$; 烧结助剂 $\mathrm{Y}_{2} \mathrm{O}_{3}$ (上海跃龙有色金属有限公司), 纯度 $>99.99 \%$, 平均粒径为 $5.0 \mu \mathrm{m}$; 高纯 $\mathrm{N}_{2}$ (纯度 $>99.9 \mathrm{wt} \%$ ); 粘结 剂 Isobam 104\#(Kuraray); 发泡剂没食子酸正丙酯 (n-Propyl gallate, 国药集团化学试剂有限公司)。

\section{2 样品制备}

将 Isobam 溶于去离子水中, 加入 $\mathrm{Y}_{2} \mathrm{O}_{3} 、 \mathrm{Si}_{3} \mathrm{~N}_{4}$ 粉, 然后将混合物转移到聚四氟乙烯球磨罐中, 以 氮化硅球为球磨介质, $300 \mathrm{r} / \mathrm{min}$ 球磨搅拌 $1 \mathrm{~h}$ 后加入 发泡剂没食子酸正丙酯(PG), 继续 $300 \mathrm{r} / \mathrm{min}$ 搅拌 $2 \mathrm{~h}$ 得到未完全发泡的水基浆料。Isobam、 $\mathrm{PG} 、 \mathrm{Y}_{2} \mathrm{O}_{3}$ 和 $\mathrm{Si}_{3} \mathrm{~N}_{4}$ 的质量比为 $0.4: 2.5: 5: 100$, 浆料固含量 为 $55 \mathrm{wt} \%$ 。将搅拌均匀的浆料浇注在模具内, 然后 整体置于真空干燥箱中, 保持温度为 $30^{\circ} \mathrm{C}$, 抽真空 并保压, 保持样品环境气压分别为 $80 、 50 、 30 、 9 \mathrm{kPa}$, 对应样品编号分别为 $1 、 2 、 3 、 4$ 。待坏体干燥后脱 模取出, 以 $5^{\circ} \mathrm{C} / \mathrm{min}$ 速率升温至 $600^{\circ} \mathrm{C}$, 保温 $2 \mathrm{~h}$ 除 去有机物, 然后在 $0.5 \mathrm{MPa}$ 气压下动态 $\mathrm{N}_{2}$ 环境中以 $10^{\circ} \mathrm{C} / \mathrm{min}$ 速率升温至 $1100^{\circ} \mathrm{C}$, 最后以 $3^{\circ} \mathrm{C} / \mathrm{min}$ 速率
升温到 $1700^{\circ} \mathrm{C}$, 保温 $2 \mathrm{~h}$, 随炉冷却即得具有连续梯 度分布的氮化硅多孔陶瓷, 其制备工艺流程如图 1 所示。

\section{3 样品表征}

用阿基米德法测试样品的气孔率和体积密度; 用日本理学电机公司的 D/MAX 型 X 射线衍射仪对 烧结产物进行物相分析; 采用日本 KETENCE 生产 的 VHX-2000E 光学显微镜观察样品的宏观结构; 用日本 JEOL 公司的 JSM-5690 型扫描电子显微镜观 察样品的断口形貌。

\section{2 结果和讨论}

\section{1 梯度形成原理}

注浆成型结合真空发泡制备梯度多孔氮化硅陶 瓷的原理如图 2 所示。成型模具由两部分组成, 方 形或圆柱形的柱状模具和石膏平板，结合部位用凡 士林密封。加入发泡剂的浆料在球磨搅拌作用下形 成无数小泡沫, 这些泡沫由 PG 支链与空气接触的 疏水油性基团形成，水基浆料则包覆在泡沫的周围， 并与 PG 分链上的水性基团以氢键结合形成比较稳 定的结构 ${ }^{[12-13]}$, 与蛋白质发泡原理类似。在负压条 件下，表层浆料中的泡沫会膨胀，当膨胀到一定体 积后，表层泡沫在表面张力作用下破裂形成浆料薄

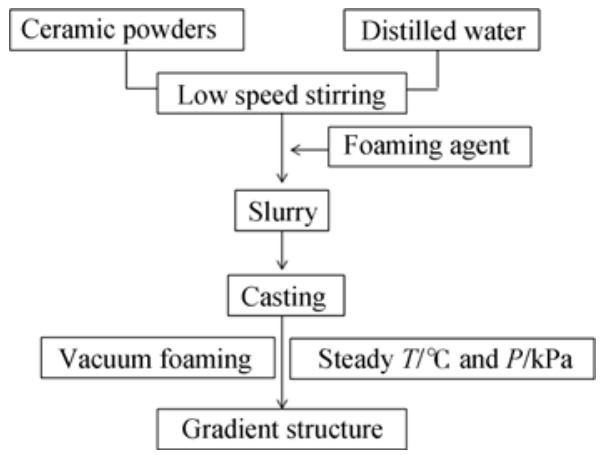

图 1 注浆成型结合真空发泡制备梯度多孔氮化硅工艺流程图 Fig. 1 Flow chart of slip casting and vacuum foaming method for gradient porous silicon nitride

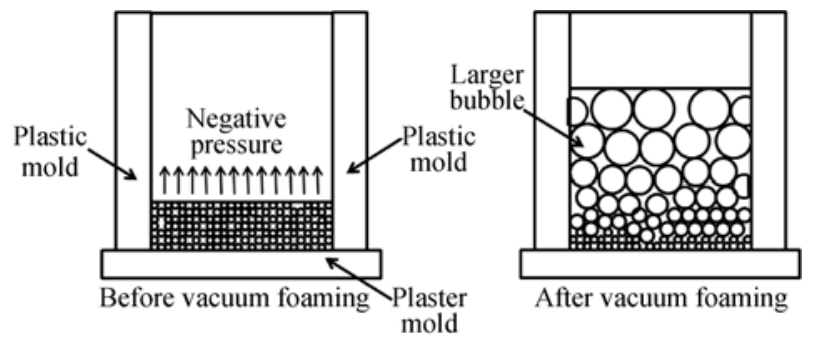

图 2 梯度形成原理图

Fig. 2 Process of forming gradient structure 
层覆盖在浆料表面。表层以下的泡沫不会直接破裂 而成为浆料层，相邻泡沫间的浆料薄膜在负压作用 下变薄, 无法作为支撑墙时, 该泡沫墙随之破裂, 两个泡沫形成新的更大体积的泡沫 ${ }^{[14]}$ 。但是, 随着 浆料深度增加, 受到上层浆料重力越大, 引起气泡 膨胀的外力减小, 体积无法快速胀大, 因而模具中 的浆料整体形成了自上而下孔径逐渐减小的梯度多 孔结构。底层的石膏模具则加速了浆料的干燥过程, 外界恒定的温度也促进了浆料中水分的蒸发, 最后 水基浆料快速脱去一部分水分后形成了具有稳定梯 度结构的坏体。

Studart 等 ${ }^{[15]}$ 曾研究过陶瓷泡沫的形成过程, 即排水、聚结(膜破裂)和奥斯特瓦尔德熟化。其中, 排水过程即气泡和浆料在重力作用下的分离过程, 加上外界负压作用, 导致浆料下沉和气泡上升; 聚 结即小气泡长大或被大气泡吞并, 大气泡继续膨胀 或破裂的过程，该过程主要由相邻气泡间的范德华 力控制; 而奥斯特瓦尔德熟化过程主要由不同孔径 大小气泡的拉普拉斯压力控制, 当气液界面能足够 大时，相邻气泡则有可能合并为一个。

\section{2 物相组成}

图 3 为样品 3 的坏体和烧结后样品的 XRD 图 谱, 可以发现坏体主相为 $\alpha-\mathrm{Si}_{3} \mathrm{~N}_{4}$, 而烧结后样品主 相为 $\beta-\mathrm{Si}_{3} \mathrm{~N}_{4}$ 。

\section{3 气压对性能的影响}

表 1 为不同气压下制备样品气孔率数据, 随着 气压从 $80 \mathrm{kPa}$ 降低到 $9 \mathrm{kPa}$, 浆料中泡沫负压增大, 因 而气孔率随之增大, 密度降低。然而当气压从 $30 \mathrm{kPa}$ 降低到 $9 \mathrm{kPa}$ 时, 样品气孔率无明显增大, 说明当气 压小于 $30 \mathrm{kPa}$ 时, 气压已不是控制气孔率变化的主 要因素。

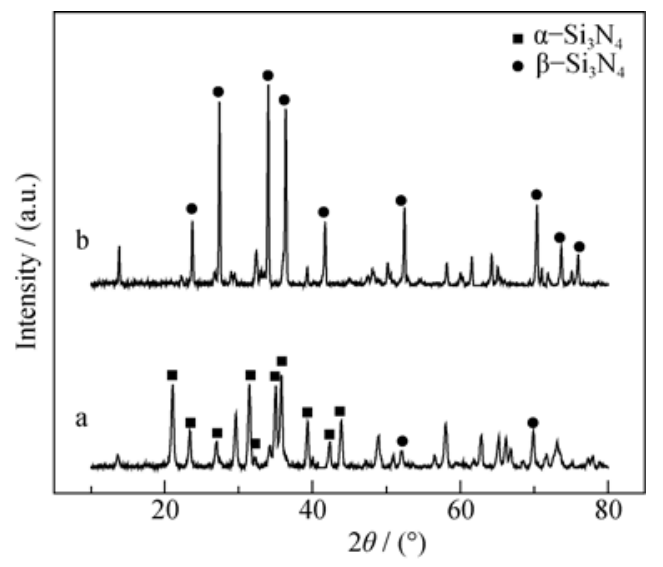

图 $330 \mathrm{kPa}$ 气压下制备的样品坏体(a)和烧结后样品(b)的 XRD 图谱

Fig. 3 XRD patterns of green body (a) and sample prepared under $30 \mathrm{kPa}$ atmosphere pressure (b)
表 1 不同气压下制备样品密度和气孔率测试值

Table 1 Densities and porosities of samples prepared under different atmosphere pressures

\begin{tabular}{ccccc}
\hline Samples & 1 & 2 & 3 & 4 \\
\hline Pressure $/ \mathrm{kPa}$ & 80 & 50 & 30 & 9 \\
Density $/\left(\mathrm{g} \cdot \mathrm{cm}^{-3}\right)$ & 1.41 & 0.84 & 0.61 & 0.66 \\
Porosity $/ \%$ & 59.01 & 75.50 & 82.20 & 80.85 \\
\hline
\end{tabular}

图 4 为不同气压下制备样品的光学显微镜照片, 其中左侧为样品底部, 不同样品呈现出从底部至顶部 (图中从左至右)明显的孔径梯度趋势(对应于图 4(b) 4(d)。 $80 \mathrm{kPa}$ 气压下制备样品的内部呈现均匀的 气孔分布。而当气压降低到 $50 \mathrm{kPa}$, 样品中气孔分布 逐渐出现梯度分布趋势，且样品气孔孔径明显增大， 样品中大气孔的分部越来越分散。这是由于气压增大, 导致大泡沫上升的吸引力减小, 因而可以保留在浆料 下部, 最终成为原位气孔(图 4(b) $)^{[15]}$ 。当气压降低到 $30 \mathrm{kPa}$ 时, 样品内部已出现明显的由底部至顶部的孔 径梯度(图 4(c)从左至右)。气压进一步降低到 $9 \mathrm{kPa}$ 时, 样品的最大孔径尺寸接近 $1 \mathrm{~mm}$ (图 4(d))。

图 5 为样品 $1(\mathrm{a} \sim \mathrm{c})$ 和样品 $4(\mathrm{~d} \sim \mathrm{f})$ 的显微形貌照 片, 可以看出样品 1 由于在高气压条件下未完成真 空发泡过程，因而样品断面只生成了极少量的小气 孔, 如图 5(a)所示。样品 4 内部的泡沫孔为近似球 形，部分泡沫孔上会有 “窗口” 出现，如图 5(d, e) 箭头所示。当气由于温度或其他原因膨胀而导致气 压大于气泡膜表面的屈服应力时，泡沫膜即破裂， 在气孔壁上形成 “窗口” 形貌 ${ }^{[16]}$ 。孔中 $\beta-\mathrm{Si}_{3} \mathrm{~N}_{4}$ 晶 粒生长良好, 具有较好的长径比, 如图 5(f) 所示。

图 6 为样品 1 和样品 4 孔径分布曲线。对比可 知, 采用 $80 \mathrm{kPa}$ 气压制备的样品 1 孔径集中在 $0.5 \mu \mathrm{m}$ 附近，而采用 $9 \mathrm{kPa}$ 气压制备的样品孔径在

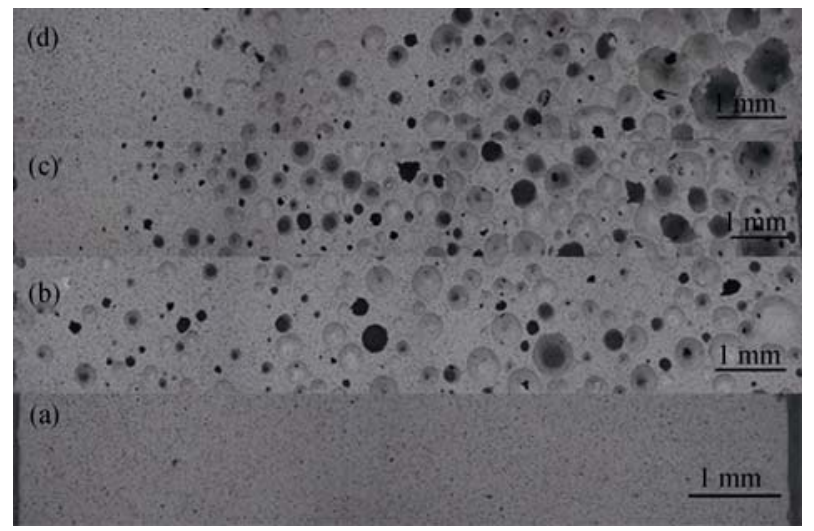

图 4 不同气压下制备样品光学显微照片

Fig. 4 Optical microscopy morphologies of samples prepared under different atmosphere pressures

(a) $80 \mathrm{kPa}$; (b) $50 \mathrm{kPa}$; (c) $30 \mathrm{kPa}$; (d) $9 \mathrm{kPa}$ 

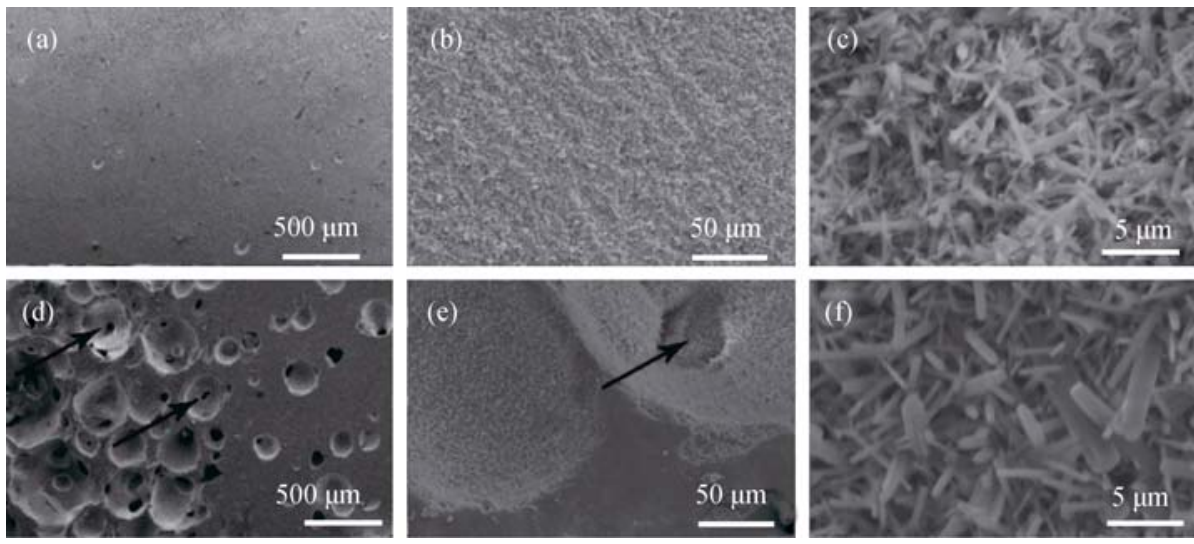

图 5 不同样品的 SEM 照片

Fig. 5 SEM images of different samples

(a, b, c) Sample1; (d, e, f) Sample 4. The arrow in (e) shows the "window" forming on the foam surface

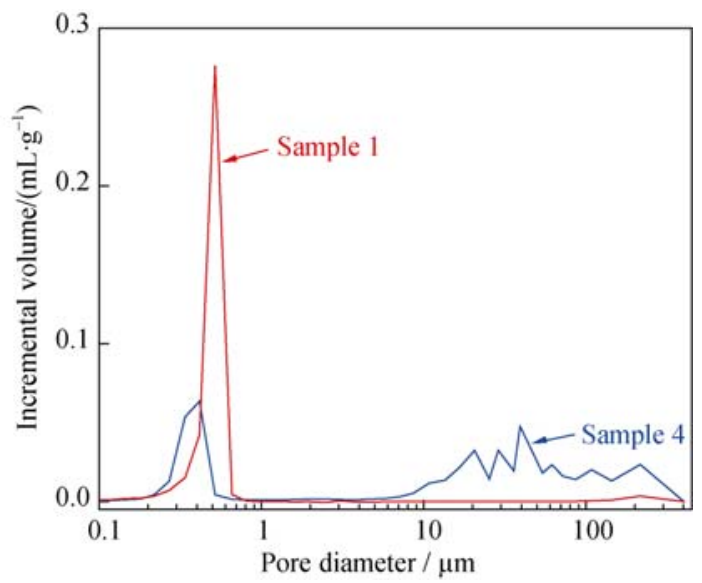

图 6 不同气压下制备样品孔径分布

Fig. 6 Pore diameter distribution of samples prepared under different atmosphere pressures

0.5、20、30、40、60、100 和 $200 \mu \mathrm{m}$ 附近明显集 中，说明该样品具有明显孔径梯度结构。

\section{3 结论}

通过结合注浆成型和真空发泡法制备出具有 明显梯度结构的多孔氮化硅陶瓷。该工艺具有简 易、快速和低成本的特点, 为梯度多孔陶瓷的制备 工艺提供了新的思路。研究发现环境气压对样品的 气孔率和梯度结构有较明显影响, 当气压从 $80 \mathrm{kPa}$ 降低到 $9 \mathrm{kPa}$ 时, 样品气孔率从 $59.01 \%$ 增大到了 $80.85 \%$ 。随着气压降低, 样品的梯度结构趋于明显, 当气压达到 $9 \mathrm{kPa}$ 时, 压录法测试表明样品呈现明显 的分散孔径分布，具有 $0.5 、 20 、 30 、 40 、 60 、 100$ 和 $200 \mu \mathrm{m}$ 等多种气孔孔径值。

\section{参考文献:}

[1] PETZOW G., HERRMANN M. Silicon nitride ceramics. Structure and Bonding, 2002, 102(1): 47-167.
[2] ZENG Y P, JIANG D L, WATANABLE T. Fabrication and properties of tape-cast laminated and functionally gradient alumina-titanium carbide materials. Journal of the American Ceramic Society, 2000, 83(12): 2999-3003.

[3] XIA Y F, ZENG Y P, JIANG D L. Mechanical and dielectric properties of porous $\mathrm{Si}_{3} \mathrm{~N}_{4}$ ceramics using PMMA as pore former. Ceramics International, 2011, 37(8): 3775-3779.

[4] YAO D X, ZENG Y P, ZUO K H, et al. The effects of BN addition on the mechanical properties of porous $\mathrm{Si}_{3} \mathrm{~N}_{4} / \mathrm{BN}$ ceramics prepared via nitridation of silicon powder. Journal of the American Ceramic Society, 2011, 94(3): 666-670.

[5] ZHANG F, QI C X, WANG S, et al. A study on preparation of cordierite gradient pores porous ceramics from rectorite. Solid State Sciences, 2011, 13(5): 929-933.

[6] BRETCANU O, SAMAILlE C, BOCCACCINI A R. Simple methods to fabricate Bioglass (R)-derived glass-ceramic scaffolds exhibiting porosity gradient. Journal of Materials Science, 2008, 43(12): 4127-4134.

[7] KINEMUCHI Y, WATARI K, UCHIMURA S. Grading porous ceramics by centrifugal sintering. Acta Materialia, 2003, 51(11): 3225-3231.

[8] XIANGMING L, PUTE W, DELAN Z. Fabrication and properties of porous $\mathrm{Si}_{3} \mathrm{~N}_{4}-\mathrm{SiO}_{2}$ ceramics with dense surface and gradient pore distribution. Ceramics International, 2014, 40(3): 5079-5084.

[9] ZHANG S X, ONG Z Y, LI T, et al. Ceramic composite components with gradient porosity by powder injection moulding. Materials \& Design. 2010, 31(6): 2897-2903.

[10] KATO M, GOTO Y, FUKASAWA T. Rheological characterization of beta-sialon and $\mathrm{Si}_{3} \mathrm{~N}_{4}$ slips and fabrication of multilayered composites by slip casting. Journal of Materials Science Letters, 1997, 16(24): 2055-2057.

[11] YAO D X, XIA Y F, ZUO K H, et al. Gradient porous silicon nitride prepared via vacuum foaming and freeze drying. Materials Letters, 2015, 141(1): 138-140.

[12] GARRN I, REETZ C, BRANDES N, et al. Clot-forming: the use of proteins as binders for producing ceramic foams. Journal of the European Ceramic Society, 2004, 24(3): 579-587.

[13] JUILLERAT F K, GONZENBACH U T, ELSER P, et al. Microstructural control of self-setting particle-stabilized ceramic foams. Journal of the American Ceramic Society, 2011, 94(1): 184-190.

[14] SEPULVEDA P, BINNER J G P. Processing of cellular ceramics by foaming and in situ polymerization of organic monomers. Journal of the European Ceramic Society, 1999, 19(12): 2059-2066.

[15] STUDART A R, GONZENBACH U T, TERVOORT E, et al. Processing routes to macroporous ceramics: a review. Journal of the American Ceramic Society, 2006, 89(6): 1771-1789.

[16] YIN L Y, ZHOU X G, YU J S, et al. Protein foaming method to prepare $\mathrm{Si}_{3} \mathrm{~N}_{4}$ foams by using a mixture of egg white protein and whey protein isolate. Ceramics International, 2014, 40(8): 11503-11509. 